\title{
Comparative Uptake of Chlorantraniliprole and Flubendiamide in the Rice Plant
}

\author{
Xiao-jun Chen ${ }^{1,2}$, Ya-jun Ren ${ }^{1,2}$, Zhi-yuan Meng ${ }^{1,2}$, Chun-liang $\mathrm{Lu}^{1}$, Hao-tian Gu${ }^{1,2} \&$ Yi-qing Zhuang ${ }^{3}$ \\ ${ }^{1}$ Joint International Research Laboratory of Agriculture \& Agri-Product Safety, Yangzhou University, Yangzhou, \\ Jiangsu, P. R. China \\ ${ }^{2}$ School of Horticulture and Plant Protection, Yangzhou University, Yangzhou, Jiangsu, P. R. China \\ ${ }^{3}$ Zhenjiang Academy of Agricultural Sciences, Zhenjiang, Jiangsu, P. R. China \\ Correspondence: Xiao-jun Chen, School of Horticulture and Plant Protection, Yangzhou University, Yangzhou, \\ Jiangsu 225009, P. R. China. E-mail: cxj@yzu.edu.cn
}

Received: September 8, 2015

Accepted: October 25, 2015 Online Published: November 15, 2015

doi:10.5539/jas.v7n12p238

URL: http://dx.doi.org/10.5539/jas.v7n12p238

\begin{abstract}
Chlorantraniliprole and flubendiamide as novel commercial insecticides could control almost all economically important lepidopteran insects and a number of key pests in vegetables and rice. At present, no researches were focused on the comparative uptake of chlorantraniliprole and flubendiamide in protected rice plants. Uptake of chlorantraniliprole or flubendiamide was investigated through hydroponic experiment or foliar absorption experiments. The results indicated that chlorantraniliprole had uptake character in rice plants and could only transport upward in the rice plant while flubendiamide had no uptake character in rice plants. Their uptake characteristic are a factor in determining their actions and toxicology,enrichment parts of the protected rice plants, persistence, metabolic processes and residual dynamics in protected rice plants.
\end{abstract}

Keywords: chlorantraniliprole, flubendiamide, uptake

\section{Introduction}

Chlorantraniliprole and flubendiamide are novel commercial insecticides which can control almost all economically important lepidopteran insects and a number of key coleopteran, dipteran, hemipteran, and isopteran pests in fruits, vegetables and rice (Lahm et al., 2005, 2007, 2009; Hannig et al.,2009). The intended use of chlorantraniliprole or flubendiamide as insecticides included the Ostrinia furnacalis, Cnaphalocrocis medinalis, Chilo suppressalis, Tryporyza incertulas, Helicoverpa armigera and others (Hoffmann et al., 2009; Ioriatti et al., 2009; Rhainds \& Sadof, 2009; Spomer et al., 2009; Cao et al., 2010). At present, researches of chlorantraniliprole or flubendiamide focus on chemical synthesis routes of chlorantraniliprole or flubendiamide (Liu et al., 2010), field control efficacy of chlorantraniliprole or flubendiamide preparations, and its insecticidal spectrum (Cao et al., 2009). Moreover, some studies focus also on the residual effects of chlorantraniliprole or flubendiamide in some fruits, vegetables or water which includes the residues and degradation dynamics of chlorantraniliprole or flubendiamide in soil or other environmental media (Caboni et al., 2008; Bu et al., 2008; Grant et al., 2010; Qin et al., 2010; Gaddamidi et al., 2011; Chen et al., 2012, 2014).

The most concerning problem on pesticide preparation was the uptake characteristic of pesticides in protected plants when pesticide preparations were used to control plant insects or diseases. This is a significant factor in determining the actions and toxicology of pesticide, enrichment parts of the protected plants, persistence, metabolic processes and residual dynamics in protected plants. On the other hand, researches of uptake of chlorantraniliprole in the velvetleaf were reported by Chen (Chen et al., 2013), and no researches were focused on the comparative uptake of chlorantraniliprole and flubendiamide in protected plants such as rice plants. The objective of this study was to comparatively evaluate the uptake and translocation of chlorantraniliprole and flubendiamide in the rice plant through hydroponic experiment or smeared on the rice leaves. Findings from this study may be used to prioritize chlorantraniliprole and flubendiamide for future evaluations, and to improve understanding of the pesticides utilization efficiency. 


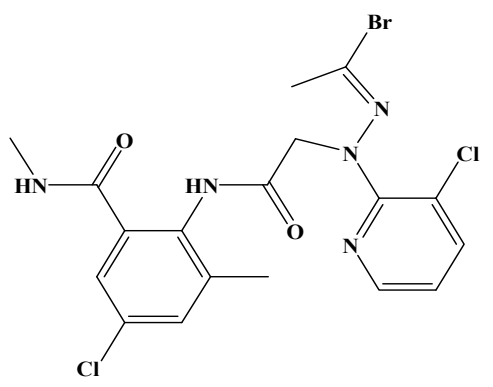<smiles>Cc1cc(C(F)(F)F)ccc1NC(=O)c1cccc(I)c1C(=O)NC(C)(C)CC(C)(F)F</smiles>

Figure 1. Chemical structure of compound chlorantraniliprole (left) and flubendiamide (right)

\section{Materials and Methods}

\subsection{Chemicals and Materials}

The instruments were BS210S electronic balance, SB-1000 rotary vacuum evaporator and THZ-82A vibrating machine made by Sartorius company of Germany, Eyela company of Japan and FuHua Company of Jiangsu province, China, respectively. Agilent 1200 Series HPLC system equipped with an Agilent 6460 Triple Quadrupole LC/MS system was made by Agilent Co. (USA).

Chlorantraniliprole (purify 99.0\%) and flubendiamide (purify 98.52\%) were purchased from Chemservice, USA, Fluka Company (USA), respectively. Dehydration magnesium sulfate, N-propyl ethylenediamine (PSA) and $\mathrm{C}_{18}$ were obtained from DIMA Technology Inc. HPLC grade solvents acetonitrile were obtained from Tedia Inc. USA. Water was used as the mobile phase in HPLC and was redistilled in a glass apparatus. Sodium chloride was obtained from Tianjin Chemical Reagent Factory and was analysis reagent.

\subsection{Rice Seeds and Rice Nutrient Solution}

Full rice seeds (Zhenjiang 2) were selected and soaked in the water for $12 \mathrm{~h}$ and the seeds were disinfected with sodium hypochlorite for $20 \mathrm{~min}$. Then the seeds were rinsed with water and put in the shade at $35{ }^{\circ} \mathrm{C}$ to pregermination. When the rice seedlings had grown and some rice seedings was transplanted into the nutrient solution. The composition of rice nutrient solution (consisted of major element and minor elements): major elements in nutrient $\left(\mathrm{mg} \cdot \mathrm{L}^{-1}\right): \mathrm{Ca}\left(\mathrm{NO}_{3}\right)_{2} \cdot 2 \mathrm{H}_{2} \mathrm{O} 89, \mathrm{MgSO}_{4} \cdot 7 \mathrm{H}_{2} \mathrm{O} 250,\left(\mathrm{NH}_{4}\right)_{2} \mathrm{SO}_{4} 49, \mathrm{KH}_{2} \mathrm{PO}_{4} 34, \mathrm{FeCl}_{3}$; ; minor elements in nutrient $\left(\mu \mathrm{g} \cdot \mathrm{L}^{-1}\right): \mathrm{H}_{3} \mathrm{BO}_{3} \quad 2.86, \mathrm{ZnSO}_{4} \cdot 7 \mathrm{H}_{2} \mathrm{O} \quad 0.22, \mathrm{MnCl}_{2} \cdot 4 \mathrm{H}_{2} \mathrm{O} \quad 1.81, \mathrm{CuSO}_{4} \cdot 5 \mathrm{H}_{2} \mathrm{O} \quad 0.08$, $\mathrm{H}_{2} \mathrm{MoO}_{4} \cdot \mathrm{H}_{2} \mathrm{O} 0.02$, citric acid 2.00 and so on.

\subsection{Experiment Methods}

\subsubsection{Determinations of Recoveries Chlorantraniliprole or Flubendiamide in Rice Plants}

Rice leaf or rice stem samples ( $5 \mathrm{~g}$ ) were weighed separately in a homogenate cup, and $30 \mathrm{~mL}$ of acetonitrile was added. After mashing the samples by a high-speed homogenizer for $3 \mathrm{~min}$, chlorantraniliprole or flubendiamide was added to the samples until the final concentrations of chlorantraniliprole or flubendiamide were 5.00, 1.00, and $0.20 \mu \mathrm{g} \mathrm{g}^{-1}$, respectively. A blank control group was also set up, and all experiments were repeated thrice. Then, $1.5 \mathrm{~g}$ of sodium chloride and $6 \mathrm{~g}$ of anhydrous magnesium sulfate were added in the samples prior to 5 min agitation in a rotary shaker at $4000 \mathrm{r} \mathrm{min}^{-1}$. About $2 \mathrm{~mL}$ of the upper mixture was collected, added to the centrifuge tubes containing $\mathrm{MgSO}_{4}(150 \mathrm{mg})$, PSA $(25 \mathrm{mg})$, and $\mathrm{C}_{18}(25 \mathrm{mg})$, and agitated for $5 \mathrm{~min}$ in a rotary shaker at $4000 \mathrm{r} \mathrm{min}^{-1}$. The sample solution $(0.60 \mathrm{~mL})$ was diluted to $1.0 \mathrm{~mL}$ of distilled water. The sample solution was filtered through a $0.22 \mu \mathrm{m}$ membrane and subjected to LC-MS/MS chromatographic analysis in MRM mode. Three replicates for each level were analyzed by LC-MS/MS.

\subsubsection{Investigation of Uptake of Chlorantraniliprole or Flubendiamide through Hydroponic Experiment}

Standard stock solutions of chlorantraniliprole or flubendiamide $\left(2000 \mu \mathrm{g} \cdot \mathrm{mL}^{-1}\right)$ were prepared in N,N-dimethyl formamide by weighing chlorantraniliprole $(0.1010 \mathrm{~g})$ or flubendiamide $(0.1015 \mathrm{~g})$ of the analytic reagent-grade $\mathrm{N}, \mathrm{N}$-dimethyl formamide into a $50 \mathrm{~mL}$ volumetric flask and diluting to volume, respectively. The solutions were stored in the dark at $4{ }^{\circ} \mathrm{C}$ until use. Solutions of chlorantraniliprole or flubendiamide $\left(200,50 \mu \mathrm{g} \cdot \mathrm{mL}^{-1}\right)$ were prepared in nutrient solution by measuring $10,2.5 \mathrm{~mL}$ standard stock solutions of chlorantraniliprole or flubendiamide $\left(2000 \mu \mathrm{g} \cdot \mathrm{mL}^{-1}\right)$ with $0.5 \mathrm{~mL}$ Tween-80 into a $100 \mathrm{~mL}$ volumetric flask and diluting to volume with nutrient solution, respectively. The nutrient solution for control treatment had the same volume of N,N-dimethyl formamide and Tween-80.

Some rice plants were planted in the nutrient solution of the rice for uptake experiments through hydroponic 
experiment. The rice plants were then transferred to a $500-\mathrm{mL}$ glass jar filled with nutrient solution consisting of different concentration of chlorantraniliprole or flubendiamide $\left(200,50 \mu \mathrm{g} \cdot \mathrm{mL}^{-1}\right)$, respectively. The rice roots were completely submerged in solution. After treatment the seedlings were cultivated under normal conditions until sampling. The rice plants were harvested after the rice plants that had grown in the rice nutrient solution for 24, 48 and $72 \mathrm{~h}$. After sampling the roots were washed with ultrapure water and dried with absorbent paper.

The whole rice plant was separated into two parts (the root of rice plant part and the rice plant above the liquid level of the rice nutrient solution part). And then each part sample $(5 \mathrm{~g})$ was weighted and extracted with acetonitrile, treated according to the method of sequence 1.3.1 and content of chlorantraniliprole or flubendiamide was determintated in each part by LC-MS/MS. Each experiment repeated for three replicates.

\subsubsection{Investigation of Uptake of Chlorantraniliprole or Flubendiamide through Smeared on the Rice Plant Leaves}

Solutions of chlorantraniliprole or flubendiamide $\left(100 \mu \mathrm{g} \cdot \mathrm{mL}^{-1}\right)$ were prepared in nutrient solution by measuring $5 \mathrm{~mL}$ standard stock solutions of chlorantraniliprole or flubendiamide $\left(2000 \mu \mathrm{g} \cdot \mathrm{mL}^{-1}\right)$ with $0.5 \mathrm{~mL}$ Tween-80 into a $100 \mathrm{~mL}$ volumetric flask and diluting to volume with nutrient solution, respectively.

2.3.3.1 Determination of the Uptake of Chlorantraniliprole or Flubendiamide Smeared on the Leaves near the Roots through Foliar Absorption Experiments

After germination described previously, the seedlings of rice were transferred to plastic pots containing loamy soil and cultivated under the same conditions described. One seedling was planted into each container.

The leaves near the roots was evenly smeared with $5 \mathrm{~mL}$ of solution containing chlorantraniliprole or flubendiamide solution $\left(100 \mu \mathrm{g} \cdot \mathrm{mL}^{-1}\right)$ and covered by a vent bag to prevent other blades from becoming contaminated. At the same time, in order to prevent the droplets from dropping into other leaves or the soil, plastic was used to cover the leaves and the soil. When the droplets on the leaves were dried, the plastic was taken away. The rice leaves were harvested after treated for 24,48 and $72 \mathrm{~h}$. The rice leaves were separated into two parts (the leaves near the roots part and above the leaves near the roots part). And then each part sample (5 g) was weighted and extracted with acetonitrile, treated according to the method of sequence 2.3.1 and content of chlorantraniliprole or flubendiamide determintated in each part by LC-MS/MS. Each experiment repeated for three replicates.

2.3.3.2 Determination of Uptake of Chlorantraniliprole or Flubendiamide Smeared on the Stem Leaves through Foliar Absorption Experiments

The stem leaves were evenly smeared with $5 \mathrm{~mL}$ of solution containing chlorantraniliprole or flubendiamide solution $\left(100 \mu \mathrm{g} \cdot \mathrm{mL}^{-1}\right)$ and covered by a vent bag to prevent other blades from becoming contaminated. Treated methods were according to the method of sequence as above 2.3.3.1. The content of chlorantraniliprole or flubendiamide was determintated in each part by LC-MS/MS. Each experiment repeated for three replicates.

\subsection{LC-MS/MS Detection Parameters of Chlorantraniliprole or Flubendiamide}

The samples above were determinated and analyzed by LC-MS/MS. Determination method of chlorantraniliprole or flubendiamide in the rice plant was described by some literatures (Caboni et al., 2008; Chen et al., 2012). LC analysis was performed with an Agilent 1200 HPLC system equipped with a binary pump, auto plate-sampler, column oven, and diode-array detector. Separation was performed on Agilent Eclipse Plus chromatographic columns $\mathrm{C}_{18}(4.6 \mathrm{~mm} \times 150 \mathrm{~mm}$ (i.d.), $5 \mu \mathrm{m})$ at $20^{\circ} \mathrm{C}$, with mobile solvents consisting of methanol: ammonium acetate with $1 \% 5 \mathrm{mmol} \mathrm{L}^{-1}$ acetic acid $=60: 40(\mathrm{~V}: \mathrm{V})$, isocratic at $1 \mathrm{~mL} \mathrm{~min}^{-1}$. Aliquots of $5 \mu \mathrm{L}$ were injected directly to the LC-MS/MS system to test flubendiamide and quantified with external standard peak area. Mass spectra was recorded on an Agilent 6460 triple quadrupole (QQQ) mass spectrometer equipped with an ESI source. System control and data acquisition were controlled by Agilent Mass Hunter software. Detailed MS conditions were: cluster voltage: $-120 \mathrm{~V}$; gas temperature: $300{ }^{\circ} \mathrm{C}$, gas flow $10 \mathrm{~L} \mathrm{~min}^{-1}$, nebulizer pressure: $15 \mathrm{psi}$, sheath gas temperature: $250{ }^{\circ} \mathrm{C}$; sheath gas flow: $7 \mathrm{~L} \mathrm{~min}^{-1}$, capillary voltage: $4 \mathrm{kV}$, nozzle voltage: $500 \mathrm{~V}$. ESI was operated in the negative ion mode in the MRM (multiple reaction monitoring). Full-scan spectra were obtained in the ranges of 0-500 for chlorantraniliprole or flubendiamide.

\subsection{Statistical Analysis}

All data were analyzed by analysis of Duncan multiple comparison. All the experiments were repeated three as means \pm standard error of mean. Different uppercase letters after the number was $1 \%$ significant difference. 


\section{Results}

\subsection{LC-MS/MS Optimal Detection Condition of Chlorantraniliprole or Flubendiamide Standard}

Chlorantraniliprole or flubendiamide standard solution was injected into the instrument directly and the parent ion of the chlorantraniliprole or flubendiamide was determined by full-scan. And then the parent ion was scanned by MS and fragment ions were obtained. Qualitative and quantitative ion pairs were identified by multiple reaction ion monitoring the relative abundance of high ions (Table 1). MS/MS figure was obtained by optimizing the conditions such as the voltage and collision voltage and other parameters. For chlorantraniliprole, we observed intense fragmentation ions at $\mathrm{m} / \mathrm{z} 453,286$ and 177. Selected reaction monitoring of the precursor-product ion transition was $\mathrm{m} / \mathrm{z} 681 / 453$ for chlorantraniliprole for the quantitative ion pair. The second and third transitions were used for confirmatory purposes for samples (Figure 2). LC-MS/MS parameters and spectrum for flubendiamide was shown in Table 1 and Figure 3.

Table 1. The LC-MS/MS parameters for chlorantraniliprole and flubendiamide

\begin{tabular}{llll}
\hline Analyte & Ion pairs & Collision energy (eV) & Note \\
\hline \multirow{3}{*}{ chlorantraniliprole } & $484 / 453$ & 14 & Quantitative ion pair \\
& $484 / 286$ & 10 & Qualitative ion pair \\
& $484 / 177$ & 50 & Qualitative ion pair \\
flubendiamide & $681 / 254$ & -22 & Quantitative ion pair \\
& $681 / 272$ & -10 & Qualitative ion pair \\
$681 / 274$ & -10 & Qualitative ion pair \\
& $681 / 214$ & -48 & Qualitative ion pair \\
\hline
\end{tabular}

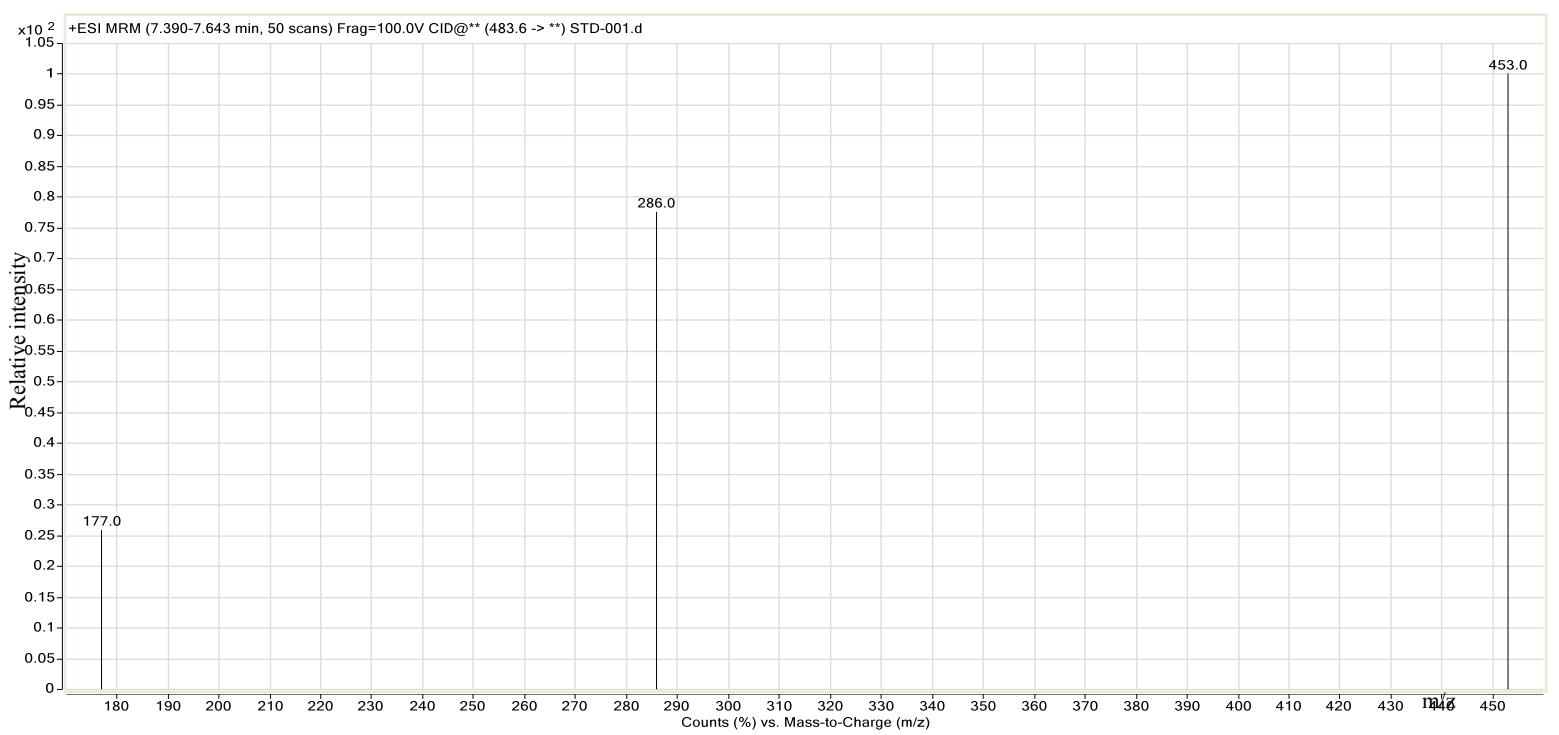

Figure 2. MS-MS spectrum of chlorantraniliprole standard by MRM mode 


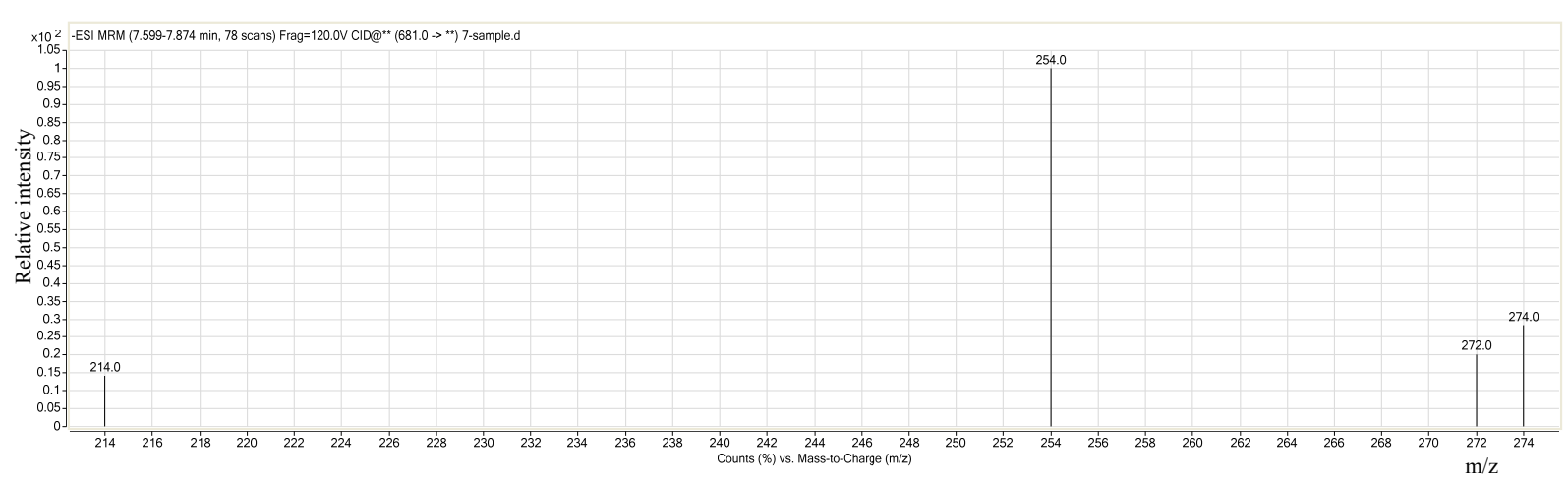

Figure 3. MS-MS spectrum of flubendiamide standard by MRM mode

\subsection{Recoveries of Chlorantraniliprole or Flubendiamide from the Rice Plant}

To know the efficiency of extraction and clean-up procedures, recovery experiments were carried out at different levels to establish the reliability and validity of analytical method. The samples were spiked at $5,1.0$, and $0.2 \mu \mathrm{g}$ $\mathrm{g}^{-1}$ respectively followed by methodology as described above. The average recoverie of chlorantraniliprole was above $80 \%$. The coefficients of variation were $1.04 \%$ to $3.54 \%$ and $1.74 \%$ to $5.44 \%$, respectively. The average recoverie of flubendiamide was above $80 \%$. The coefficients of variation were $2.69 \%$ to $4.59 \%$ and $1.95 \%$ to $5.14 \%$, respectively (Table 2). These values were in accordance to the pesticide residue criterion at different fortification levels.

Table 2. The recoveries of chlorantraniliprole and flubendiamide from the rice roots and rice leaves

\begin{tabular}{|c|c|c|c|c|c|}
\hline Insecticides & Sample & $\begin{array}{l}\text { Fortification level } \\
\left(\mu \mathrm{g} \mathrm{g}^{-1}\right)\end{array}$ & $\begin{array}{l}\text { Average recovery } \\
(\%)\end{array}$ & Standard deviation & $\begin{array}{l}\text { Coefficent of variance } \\
(\%)\end{array}$ \\
\hline \multirow[t]{6}{*}{ Chlorantraniliprole } & Rice roots & 5.0 & 90.47 & 0.0469 & 1.04 \\
\hline & & 1.0 & 90.34 & 0.0311 & 3.44 \\
\hline & & 0.2 & 85.45 & 0.0061 & 3.54 \\
\hline & Rice leaves & 5.0 & 90.53 & 0.1083 & 2.39 \\
\hline & & 1.0 & 89.57 & 0.0156 & 1.74 \\
\hline & & 0.2 & 84.57 & 0.0092 & 5.44 \\
\hline \multirow[t]{6}{*}{ Flubendiamide } & Rice roots & 5.0 & 91.95 & 0.1235 & 2.69 \\
\hline & & 1.0 & 85.39 & 0.0272 & 3.19 \\
\hline & & 0.2 & 81.87 & 0.0075 & 4.59 \\
\hline & Rice leaves & 5.0 & 94.14 & 0.0916 & 1.95 \\
\hline & & 1.0 & 92.49 & 0.0208 & 2.25 \\
\hline & & 0.2 & 86.01 & 0.0088 & 5.14 \\
\hline
\end{tabular}

Note. Mean value of three replicates.

\subsection{Uptake Results of Chlorantraniliprole or Flubendiamide in Rice Plant through Hydroponic Experiment}

When rice roots were incubated in chlorantraniliprole solution at a concentration $50 \mu \mathrm{g} \cdot \mathrm{mL}^{-1}$ through hydroponic experiment, concentration of chlorantraniliprole in the rice plant above the liquid level part was 5.13, 9.17 and $12.86 \mu \mathrm{g} \cdot \mathrm{g}^{-1}$ after treatment for 24,48 and $72 \mathrm{~h}$, respectively. When rice roots were incubated in chlorantraniliprole solution at a concentration $200 \mu \mathrm{g} \cdot \mathrm{mL}^{-1}$ through hydroponic experiment, concentration of chlorantraniliprole in the rice plant above the liquid level was $13.87,19.62$ and $22.51 \mu \mathrm{g} \cdot \mathrm{g}^{-1}$ after treatment for 24 , 48 and $72 \mathrm{~h}$, respectively. Flubendiamide was not detected in the rice plant above the liquid level of nutrient solution at a concentration 50 and $200 \mu \mathrm{g} \cdot \mathrm{mL}^{-1}$ after treatment for 24,48 and $72 \mathrm{~h}$ (Table 3). 
Table 3. The content of chlorantraniliprole or flubendiamide in rice plant above the liquid level of nutrient solution after pesticides treated through hydroponic experiment ${ }^{1), 2)}$

\begin{tabular}{|c|c|c|c|c|}
\hline \multirow{2}{*}{ Insecticides } & \multirow{2}{*}{$\begin{array}{l}\text { Treatment concentration } \\
\left(\mu \mathrm{g} \mathrm{mL} \mathbf{L}^{-1}\right)\end{array}$} & \multirow{2}{*}{$\begin{array}{l}\text { Detected time } \\
\text { (h) }\end{array}$} & \multicolumn{2}{|c|}{ Content of pesticides in the plant $\left(\mu \mathrm{g} \mathrm{g}^{-1}\right)$} \\
\hline & & & Treated root & plants above the liquid level part \\
\hline \multirow[t]{6}{*}{ Chlorantraniliprole } & 50 & 24 & $16.89 \pm 0.42 \mathrm{a}$ & $5.13 \pm 0.12 \mathrm{c}$ \\
\hline & & 48 & $13.84 \pm 0.58 \mathrm{~b}$ & $9.17 \pm 0.09 \mathrm{~b}$ \\
\hline & & 72 & $9.33 \pm 0.79 \mathrm{c}$ & $12.86 \pm 0.27 \mathrm{a}$ \\
\hline & 200 & 24 & $24.88 \pm 0.65 \mathrm{a}$ & $13.87 \pm 1.14 \mathrm{c}$ \\
\hline & & 48 & $18.97 \pm 0.47 \mathrm{~b}$ & $19.62 \pm 0.56 \mathrm{~b}$ \\
\hline & & 72 & $12.04 \pm 0.28 \mathrm{c}$ & $22.51 \pm 1.10 \mathrm{a}$ \\
\hline \multirow[t]{6}{*}{ Flubendiamide } & 50 & 24 & $17.65 \pm 0.15 \mathrm{c}$ & ND \\
\hline & & 48 & $18.29 \pm 0.41 \mathrm{~b}$ & ND \\
\hline & & 72 & $18.50 \pm 0.36 \mathrm{a}$ & ND \\
\hline & 200 & 24 & $27.91 \pm 0.52 b$ & ND \\
\hline & & 48 & $29.86 \pm 0.44 \mathrm{a}$ & ND \\
\hline & & 72 & $30.27 \pm 0.63 \mathrm{a}$ & ND \\
\hline
\end{tabular}

Note. ${ }^{1)}$ Mean value of three replicates; ${ }^{2)}$ "ND" means no detected in the detection limit.

3.4 Uptake Results of Chlorantraniliprole or Flubendiamide in Rice Plants after Smeared on Leaves through Foliar Absorption Experiments

3.4.1 Uptake Results of Chlorantraniliprole or Flubendiamide Smeared on Leaves near the Roots through Foliar Absorption Experiments

When chlorantraniliprole was smeared on the leaves near the roots through foliar absorption experiments at a concentration of $100 \mu \mathrm{g} \cdot \mathrm{mL}^{-1}$, chlorantraniliprole was found in stem leaves and its concentration was $3.41,4.18$ and $4.92 \mu \mathrm{g} \cdot \mathrm{g}^{-1}$ after treatment for 24,48 and $72 \mathrm{~h}$, respectively. Flubendiamide was not detected in the stem leaves at a concentration $100 \mu \mathrm{g} \cdot \mathrm{mL}^{-1}$ after treatment for 24,48 and $72 \mathrm{~h}$, respectively (Table 4 ).

Table 4. The content of chlorantraniliprole or flubendiamide in stem leaves after pesticides smeared on leaves near the roots through foliar absorption experiments ${ }^{1), 2)}$

\begin{tabular}{llll}
\hline \multirow{2}{*}{ Insecticides } & Detected time (h) & \multicolumn{2}{c}{ Content of pesticides in the rice plant $\left(\boldsymbol{\mu g} \mathbf{~ g}^{\mathbf{- 1}}\right)$} \\
\cline { 3 - 4 } & & Treated leaves & Stem leaves \\
\hline Chlorantraniliprole & 24 & $34.56 \pm 0.21 \mathrm{a}$ & $3.41 \pm 0.37 \mathrm{c}$ \\
& 48 & $25.88 \pm 0.17 \mathrm{~b}$ & $4.18 \pm 0.28 \mathrm{~b}$ \\
& 72 & $17.63 \pm 0.27 \mathrm{c}$ & $4.92 \pm 0.41 \mathrm{a}$ \\
\hline Flubendiamide & 24 & $35.81 \pm 0.33 \mathrm{a}$ & $\mathrm{ND}$ \\
& 48 & $33.89 \pm 0.38 \mathrm{~b}$ & $\mathrm{ND}$ \\
\hline
\end{tabular}

Note. ${ }^{1)}$ Mean value of three replicates; ${ }^{2)}$ "ND" means no detected in the detection limit.

3.4.2 Uptake Results of Chlorantraniliprole or Flubendiamide Smeared on the Stem Leaves through Foliar Absorption Experiments

When chlorantraniliprole was smeared on the stem leaves through foliar absorption experiment at a concentration of $100 \mu \mathrm{g} \cdot \mathrm{mL}^{-1}$, chlorantraniliprole was found in the stem leaves and its concentration was 41.88 , 39.56 and $37.72 \mu \mathrm{g} \cdot \mathrm{g}^{-1}$ after treatment for 24,48 and $72 \mathrm{~h}$, respectively; while no chlorantraniliprole was detected in the leaves below the stem leaves. Flubendiamide was not detected in the leaves below the stem leaves at a concentration $100 \mu \mathrm{g} \cdot \mathrm{mL}^{-1}$ after treatment for 24,48 and $72 \mathrm{~h}$ (Table 5). 
Table 5. The content of chlorantraniliprole or flubendiamide in the leaves below the stem leaves after pesticides smeared on the stem leaves through foliar absorption experiments ${ }^{1), 2)}$

\begin{tabular}{llll}
\hline \multirow{2}{*}{ Insecticides } & Detected time $(\mathbf{h})$ & \multicolumn{2}{c}{ Content of pesticides in the rice plant $\left(\boldsymbol{\mu g} \mathbf{g ~ g}^{\mathbf{- 1}}\right)$} \\
\cline { 3 - 4 } & & Treated leaves & Below stem leaves \\
\hline Chlorantraniliprole & 24 & $41.88 \pm 0.39 \mathrm{a}$ & $\mathrm{ND}$ \\
& 48 & $39.56 \pm 0.54 \mathrm{~b}$ & $\mathrm{ND}$ \\
& 72 & $37.72 \pm 0.27 \mathrm{c}$ & $\mathrm{ND}$ \\
\hline Flubendiamide & 24 & $42.79 \pm 0.94 \mathrm{a}$ & $\mathrm{ND}$ \\
& 48 & $40.23 \pm 0.83 \mathrm{~b}$ & $\mathrm{ND}$ \\
& 72 & $38.76 \pm 0.70 \mathrm{c}$ & $\mathrm{ND}$ \\
\hline
\end{tabular}

Note. ${ }^{1)}$ Mean value of three replicates; ${ }^{2)}$ "ND" means no detected in the detection limit.

\section{Discussion}

In present, chlorpyrifos, profenofos, abamectin, hexaflumuron and other pesticides that were used to control Cnaphalocrocis medinalis does not exhibit uptake character. Hence, these not be transported effectively in the plants of rice, and the efficiency of protection of new leaves were limited. Therefore, these pesticides have to be sprayed repeatedly in the rice field which can be attacked frequently by adult insects for a long period (Cao et al., 2010; Shao et al., 2011; Shen et al., 2011). Hence, some excellent insecticides were urgently developed to control rice pests or uptake characters or action mechanisms of some insecticides on the rice insects need be clarified. If chlorantraniliprole preparations could be transported in rice plants and the retention could last for 20 days, then spraying once is enough for controlling each generation of Cnaphalocrocis medinalis. Based on the current experiment, chlorantraniliprole could be detected in a conjoined stem and leaf sheath on the treated leaf when it was applied on the leaves of rice plant. However, no chlorantraniliprole was detected in other adjacent leaves. The reason for this may be that chlorantraniliprole could penetrate in rice leaves and is transported for a short distance, moving to the stem or the leaf sheath of the treated leaves. Thus, it could not be transported from one leaf to the other. It may indicate that chlorantraniliprole has limited penetrated ability, and could not be transported between leaves.

In order to improve the absorption efficiency of chlorantraniliprole in rice, enough volume of the solution should be sprayed so that it could flow onto the rice stems along the leaf sheaths. The results indicated that chlorantraniliprole had uptake in rice plants and could be transported from the bottom to the top of the plant. Therefore, it could not only be sprayed on rice leaves which could not work its potency. In order to control insect integrity, chlorantraniliprole preparations such as WG, granular formulation, water dispersible granule, could be considered for manufacturing.

\section{Conclusions}

As shown by our results, it indicated that chlorantraniliprole had uptake character in rice plants and could only transport upward in the rice plant while flubendiamide had no uptake character in rice plants.

\section{Acknowledgements}

We thank the Natural Science Foundation of Jiangsu Province (BK20130443) and Key Research and Development Program of Jiangsu province (BE2015342), the Natural Science Foundation of the Jiangsu Higher Education Institutions of China (13KJB210010), the Social Development Science and Technology Projects of Yangzhou City, China (2012110) and Graduate students' Practice Innovation Training Program of Higher School (KYLX15_1373, 201411117048Y) for providing financial support.

\section{References}

Bu, H. Y., Ou, X. M., Ma, J. K., \& Cai, D. L. (2008). Determination of chlorantraniliprole residue in environmental aquatic samples by high performance liquid chromatography. Chin J. Spect Lab., 25(6), 1230-1234.

Caboni, P., Sarais, G., Angioni, A., Vargiu, S., Pagnozzi, D., Cabras, P., \& Casida, J. E. (2008). Liquid chromatography-tandem mass spectrometric ion-switching determination of chlorantraniliprole and flubendiamide in fruits and vegetables. J. Agric. Food. Chem., 56(17), 7696-7699. http://dx.doi.org/10.1021/jf8014816 
Cao, G. C., Lu, Q., Zhang, L. L., Guo, F., Liang, G. M., Wu, K. M., ... Guo, Y. Y. (2010). Toxicity of chlorantraniliprole to Cry1Ac- susceptible and resistant strains of Helicoverpa armigera. Pestic. Biochem. Physiol., 98(1), 99-103. http://dx.doi.org/10.1016/j.pestbp.2010.05.006

Chen, X. J., Cui, H. R., Fan, S. Q., Wang, M., Lu, C. L., \& Yang, Y. Z. (2013). Uptake of chlorantraniliprole in velvetleaf (Abutilon theophrasti). J. AOAC Int., 96(1), 1-6. http://dx.doi.org/10.5740/jaoacint.12-166

Chen, X. J., Lu, C. L., Fan, S. Q., Lu, H. B., Cui, H. R., Meng, Z. Y., \& Yang, Y. Z. (2012). Determination of residual flubendiamide in the cabbage by QuEChERS-high performance liquid chromatography-tandem mass spectrometry. Bull. Environ. Contam. Toxicol., 89(5), 1021-1026. http://dx.doi.org/10.1007/s00128-012-0805-6

Chen, X. J., Wang, P., Meng, Z. Y., Chen, S., Gu, H. T., \& Sha, X. L. (2014). Degradation dynamics and residue analysis of flubendiamide in cabbage and soil by liquid chromatography-tandem mass spectrometry with dispersive solid phase extraction. Agric Sci., 5, 850-857. http://dx.doi.org/10.4236/as.2014.510091

Gaddamidi, V., Zimmerman, W. T., Ponte, M., \& Ruzo, L. (2011). Pyrolysis of $\left[{ }^{14} \mathrm{C}\right]$-chlorantraniliprole in tobacco. J. Agric. Food. Chem., 59, 9424-943216. http://dx.doi.org/10.1021/jf201995b

Grant, J., Rodgers, C. A., Chickering, C. D., Hill, S. J., \& Stry, J. J. (2010). Determination of chlorantraniliprole residues in crops by liquid chromatography coupled with atmospheric pressure chemical ionization mass spectrometry/mass spectrometry. J. AOAC Int., 93(4), 1293-1301.

Hannig, G. T., Ziegler, M., \& Marcon, P. G. (2009). Feeding cessation effects of chlorantraniliprole, a new anthranilic diamide insecticide, in comparison with several insecticides in distinct chemical classes and mode-of-action groups. Pest Manag Sci., 65(9), 969-9745. http://dx.doi.org/10.1002/ps.1781

Hoffmann, E. J., Vandervoort, C., \& Wise J. C. (2009). Curative activity of insecticides against Plum curculio (Coleoptera: Curculionidae) in tart cherries. J. Econ. Entomol., 102(5), 1864-1873. http://dx.doi.org/10.1603/029.102.0517

Ioriatti, C., Anfora, G., Angeli, G., Mazzoni, V., \& Trona, F. (2009). Effects of chlorantraniliprole on eggs and larvae of Lobesia botrana (Denis \& Schiffermuller) Lepidoptera: Tortricidae. Pest Manag Sci., 65(6), 717-722. http://dx.doi.org/10.1002/ps. 1744

Lahm, G. P., Cordova, D., \& Barry, J. D. (2009). New and selective ryanodine receptor activators for insect control. Bioorg. Med. Chem., 17(12), 4127-4133. http://dx.doi.org/10.1016/j.bmc.2009.01.018

Lahm, G. P., Selby, T. P., Freudenberger, J. H., Stevenson, T. M., Myers, B. J., Seburyamo, G., ... Cordova, D. (2005). Insecticidal anthranilic diamides: a new class of potent ryanodine receptor activators. Bioorg. Med. Chem., 15(22), 4898-4906. http://dx.doi.org/10.1016/j.bmcl.2005.08.034

Lahm, G. P., Stevenson, T. M., Selby, T. P., Freudenberger, J. H., Cordova, D., Flexner, L., ... Benner, E. A. (2007). Rynaxypyr ${ }^{\mathrm{TM}}$ : a new insecticidal anthranilic diamide that acts as a potent and selective ryanodine receptor activator. Bioorg. Med. Chem., 17(22), 6274-62793. http://dx.doi.org/10.1016/j.bmcl.2007.09.012

Liu, G. Y., Ju, X. L., Cheng, J., \& Liu, Z. Q. (2010). 3D-QSAR studies of insecticidal anthranilic diamides as ryanodine receptor activators using CoMFA, CoMSIA and DISCOtech. Chemosphere, 78, 300-306. http://dx.doi.org/10.1016/j.chemosphere.2009.10.038

Qin, D. M., Xin, Q., Xu, Y. M., Sun, Y., Liang, X. F., \& Dai, X. H. (2010). Residue determination and degradation of chlorantraniliprole in soil and tomato. J. Agro-Environment Sci., 29, 858-863.

Rhainds, M., \& Sadof, C. (2009). Control of bagworms (Lepidoptera: Psychidae) using contact and soil-applied systemic insecticides. J. Econ. Entomol., 102(3), 1164-11698. http://dx.doi.org/10.1603/029.102.0339

Schwarz, T., Snow, T. A., Santee, C. J., Mulligan, C., Class, T., Wadsley, M., \& Nanita S. (2011). QuEChERS multiresidue method validation and mass spectrometric assessment for the novel anthranilic diamide insecticides chlorantraniliprole and cyantraniliprole. J. Agric. Food. Chem., 59, 814-821. http://dx.doi.org/10.1021/jf103468d

Shao, Z. R., Li, Y. P., Shen, J. L., Zhang, S., Gao, C. F., Zhang, K. X., \& Chen, Y. (2011). Field demonstration experiment of rice plant leaf roller and striped rice plant borer with chlorantraniliprole. J. Huazhong Agric Univ., 30, 609-612.

Shen, G. F., Xu, Y. S., \& Feng, M. F. (2011). Comparison of different insecticides against Cnaphalocrocis medinalis. China Rice, 17, 49-50. 
Spomer, N. A., Kamble, S. T., \& Siegfried, B. D. (2009). Bioavailability of chlorantraniliprole and indoxacarb to eastern subterranean termites (Isoptera: Rhinotermitidae) in various soils. J. Econ. Entomol., 102(5), 1922-1927. http://dx.doi.org/10.1603/029.102.0524

\section{Copyrights}

Copyright for this article is retained by the author(s), with first publication rights granted to the journal.

This is an open-access article distributed under the terms and conditions of the Creative Commons Attribution license (http://creativecommons.org/licenses/by/3.0/). 